\title{
Study of Anisotropic Photoluminescence and Energy Transfer in Oriented Dye-incorporating Zeolite-L Monolayer
}

\author{
Jin Seok Lee \\ Department of Chemistry, Sookmyung Women's University, Seoul 140-742, Korea.E-mail: jinslee@sookmyung.ac.kr \\ Received June 4, 2010, Accepted June 11, 2010
}

\begin{abstract}
Development of the methods to organize zeolite microcrystals into closely packed and uniformly aligned monolayers on various substrates have been pursued viewing microparticles as a novel class of building blocks. We now report that the vertically aligned zeolite monolayer can be applied as novel supramolecularly organized systems for anisotropic photoluminescence in high dichroic ratio, to study energy transfer dynamics between the internal and external fluorophores, and to develop zeolite-based advanced materials. Study of polarized fluorescence spectroscopy and angle-dependent intensity change with dye molecules in different surroundings further provides insight into molecular interactions that can be used for the future design of optoelectronic device in nanometer size. In addition, this report shows that isolating of organic dye through surface treatment is crucial for preventing the egress of the incorporated dye molecules from the channels of zeolite to the solution and to enhance the anisotropic luminescence.
\end{abstract}

Key Words: Anisotropy, Photoluminescence, Energy transfer, Zeolite-L, Monolayer

\section{Introduction}

In natural photosynthesis, sunlight is absorbed by plant leaf consisting of a few hundred chlorophyll molecules. These systems allow directional energy transfer from an electronically excited molecule to an unexcited neighbor molecule in such a way that the excitation energy reaches the reaction center of photosynthesis with high probability and efficiency. Here, the anisotropic arrangement of the chlorophyll molecules is crucial for efficient energy transportation that allows the flow of energy to be controlled and directed to regions for a desired purpose. In natural photosynthesis systems, the formation of aggregates is prevented by fencing the chlorophyll molecules in polypeptide cages.

From the efforts to mimic a optoelectronic device like as natural photosynthesis systems, a number of recent attempts have been made to improve device performance by arrangement of the fluorescence molecules by various methods. Approaches include stretching-drawing, ${ }^{1,2}$ Langmuir-Blodgett technique, liquid-crystalline self-organization, ${ }^{5}$ alignment on specific substrates, ${ }^{6}$ and chemical vapor deposition technique. ${ }^{7}$ A similar approach is also possible by enclosing fluorescence molecules inside a porous material and by choosing conditions such that the cavities are able to accommodate only monomers but not aggregates. $^{8-11}$

Among the porous materials, zeolite is known the suitable hosts for specific organization of chromophores, which is inorganic crystalline aluminosilicates with pores in nanometer size, because of their well-defined internal structure with uniform cages, cavities or channels. The aluminosilicate framework of the zeolite comprises a channel system of molecular dimensions (typically $0.4-0.8 \mathrm{~nm}$ ) providing a host matrix for adsorbent molecules. Particularly, the composite materials of chromophores and crystalline molecular sieves have attracted special interest by reason of offering several advantages for applications such as tunability of their properties by variation of their components, thermal resistance of the mineral host, and chemical stability toward excited molecules. ${ }^{12}$ Therefore, the confinement of the dyes within the channels of zeolite caused by steric constraints provides a great opportunity for a variety of optical effects and attracts the great interest for new and miniaturized sensors and as intelligent materials, beyond their traditional use such as catalysts and ion exchange resin.

In this report, zeolite-L was used as a host material because it was found to be very versatile. The main channels of zeolite- $\mathrm{L}$ consist of uint cells with a length of $7.5 \AA$ in the c-direction, which they are joined by 12 -membered ring windows with a diameter of $7.1 \AA$. The largest free diameter is about $12.6 \AA$, depending on the charge compensating cations. ${ }^{8,9}$

With this background in mind, we have explored the methods of organizing zeolite microcrystals to film in the form of closely packed monolayers on various substrates as a host matrix for adsorbent molecules. ${ }^{13-16}$ Based on our previous study about the monolayer assembly of zeolites on glass by the sonication assisted methods, ${ }^{15}$ we could quickly prepare a uniaxially oriented zeolite monolayer film with a closed packing. We report herein the alignment and isolation of pyronin $\mathrm{B}\left(\mathrm{PyB}^{+}\right)$molecules used as a fluorescence dye in the nanochannels of an ordered zeolite-L monolayer matrix, using the sonication as a preparing method and the host-guest nanocomposite as anisotropic luminescence materials. $\mathrm{PyB}^{+}$ions are of appropriate size for being inserted into the channels of zeolite-L. Since the length of $\mathrm{PyB}^{+}$ion $(16.3 \AA)$ is longer than the width of the zeolite-L lobe $(12.6 \AA),{ }^{9}$ the incorporated $\mathrm{PyB}^{+}$ions are forced to be lined up along the direction of channel. We also show that surface silylation of a host-guest nanocomposite is a very simple yet highly effective method for anisotropic fluorescence with highly dichroic ratio.

\section{Experimental Section}

Materials. The cylindrical zeolite-L crystals was prepared 
according to the procedures described in our previous report. ${ }^{17}$ Pyronin $\mathrm{B}\left(\mathrm{PyB}^{+} \mathrm{FeCl}_{4}^{-}\right),(3$-aminopropyl)trimethoxysilane (AP-TMS), (3-chloropropyl)trimethoxysilane (CP-TMS), dimethylsulfoxide (DMSO), and glycerol were purchased from Aldrich and used as received. Cover glasses $\left(18 \times 18 \mathrm{~mm}^{2}\right)$ were purchased from Marienfeld and treated in a piranha solution $\left(\mathrm{H}_{2} \mathrm{SO}_{4}: 30 \% \mathrm{H}_{2} \mathrm{O}_{2}=3: 1\right)$ at $95-100{ }^{\circ} \mathrm{C}$ for $1 \mathrm{~h}$ to remove organic residues on the surface. Toluene was purchased from Junsei and distilled over sodium under argon prior to use.

Preparation of vertically aligned zeolite-L monolayer on 3chloropropyl-tethering glass. Clean cover glass plates were treated with the toluene solution of CP-TMS (a mixture of 40 $\mathrm{mL}$ of toluene and $1 \mathrm{~mL}$ of CP-TMS) at $120{ }^{\circ} \mathrm{C}$ for $3 \mathrm{~h}$ under argon. After cooling to room temperature, 3 -chloropropyl-tethering glass (CP-g) plates were successively washed with copious amounts of freshly distilled toluene and ethanol. The washed $\mathrm{CP}$-g plates were dried with a gentle stream of high purity nitrogen, and kept in desiccators. The vertically aligned zeolite-L monolayer on CP-g (v-L-g) was prepared by 'sonication with stacking between the glass plates (SS)' method according to the procedure describe in our previous report. ${ }^{15}$ Typically, a comb-shaped teflon support was placed at the bottom of the $50 \mathrm{~mL}$ round-bottomed flask charged with $40 \mathrm{~mL}$ of toluene and $50 \mathrm{mg}$ of zeolite-L microcrystals. And, a CP-g plate was interposed between two clean bare glass $(\mathrm{Bg})$ plates, and three sets of $\mathrm{Bg} / \mathrm{CP}-\mathrm{g} / \mathrm{Bg}$ stack were inserted, stack by stack, into each gap of the comb-shaped teflon support. The round-bottomed flask was placed directly above an ultrasound generator in the bath, and then the attachment reaction between zeolite-L microcrystals and CP-g was carried out for $2 \mathrm{~min}$.

Inclusion of $\mathrm{PyB}^{+}$ions into the channels of $\mathbf{v}-\mathrm{L}-\mathrm{g}$. $\mathrm{PyB}^{+}$ions were incorporated into the channels of $\mathrm{v}-\mathrm{L}-\mathrm{g}$ by aqueous ion exchange of $\mathrm{K}^{+}$ions in zeolite $\mathrm{L}$ with $\mathrm{PyB}^{+} \mathrm{FeCl}_{4}{ }^{-}(100 \mathrm{~mL}$, $0.1 \mathrm{mM}$ ) under the reflux and stirring (RS) condition for $90 \mathrm{~min}$. After rigorous washing with distilled deionized water, the $\mathrm{PyB}^{+}-$ incorporating v-L-g $\left(\mathrm{v}-\left(\mathrm{PyB}^{+}\right) \mathrm{L}-\mathrm{g}\right)$ was further washed with DMSO by soxhlet extraction until no further $\mathrm{PyB}^{+} \mathrm{FeCl}_{4}^{-}$was detected in DMSO.

Measurements of anisotropic photoluminescence. The setup is basically the same with that described in our previous report. ${ }^{9}$ Three v-(PyB $\left.{ }^{+}\right) \mathrm{L}-\mathrm{g}$ or aminopropyl-tethering v-(PyB $\left.{ }^{+}\right) \mathrm{L}-\mathrm{g}$ $\left(\mathrm{v}-\left(\mathrm{PyB}^{+}\right) \mathrm{L}^{\mathrm{AP}}-\mathrm{g}\right)$ plates were placed horizontally on a stack of five bare glass plates placed horizontally in a quartz container $\left(20 \times 20 \times 10 \mathrm{~mm}^{3}\right)$ charged with glycerol as an index-matching fluid. The zero-order $\lambda / 2$-waveplate was used to change the angle of linearly polarized incident light to vertical (V) or horizontal $(\mathrm{H})$ direction, and a compensator to change the linearly polarized light from the $\lambda / 2$-waveplate to circularly polarized light. A vertically, horizontally or circularly polarized beam $(\lambda=514.5 \mathrm{~nm})$ generated from an $\mathrm{Ar}^{+}$ion laser (Coherent) was introduced into the stack of $\mathrm{V}-\left(\mathrm{PyB}^{+}\right) \mathrm{L}-\mathrm{g}$ or $\mathrm{V}-\left(\mathrm{PyB}^{+}\right) \mathrm{L}^{\mathrm{AP}}-\mathrm{g}$, and the produced fluorescent light was introduced into a spectrometer (Horiba Jobin Yvon, TRIAX 550) equipped with a chargecoupled device $(C C D)$ array $(2048 \times 512)$ detector after passing through an achromatic $\lambda / 2$-waveplate to rotate the polarization to $0^{\circ}$ (horizontal) and a linear polarizer fixed at $0^{\circ}$ (horizontal). Care was taken to ascertain that the detection system does not introduce any systematic anisotropy. This was checked by mea- suring $\mathrm{PyB}^{+}$dissolved in glycerol with circularly polarized laser light and obtaining the ratio of vertically-polarized to horizontally-polarized luminescence intensity of 1.05.

\section{Results and Discussions}

The morphology of zeolite-L crystal used in this report was cylindrical rod shape with the sizes of $1 \mu \mathrm{m}$ (diameter) $\times 2-3 \mu \mathrm{m}$ (length). ${ }^{9,17}$ Based on our previous study, we prepared the vertically aligned zeolite-L monolayer on CP-g (v-L-g) by 'sonication with stacking between the glass plates (SS)' method ${ }^{9,15}$ as shown Figure 1a. Pyronin B $\left(\mathrm{PyB}^{+}\right)$ions were incorporated into the channels of zeolite-L crystals by ion exchange of $\mathrm{K}^{+}$ ions of the zeolites with $\mathrm{PyB}^{+}$ions in water under the reflux and stirring $(\mathrm{RS})$ condition. And then, the $\mathrm{PyB}^{+}$-incorporating v-L-g $\left(v-\left(P^{+} B^{+}\right) L-g\right)$ was further washed with DMSO, which have higher solubility for polar $\mathrm{PyB}^{+}$molecules than water, by soxhlet extraction until no further $\mathrm{PyB}^{+} \mathrm{FeCl}_{4}{ }_{4}^{-}$was detected in DMSO to detach physically adsorbed $\mathrm{PyB}^{+}$ions from the external surface of zeolite-L crystals.

When cylindrical zeolite-L crystals were attached onto CP-g plates by the SS method for 2 min, the crystals self-assembled very tightly and vertically on CP-g plates as shown by scanning electron microscope (SEM, Figure 1b) image. Contrary to 'reflux (R)' or 'reflux and stirring (RS)' method with same reaction period, a dramatic increase in the rate of attachment was observed under the SS condition, despite the fact that the temperature was kept constant at $20^{\circ} \mathrm{C}$. And, comparing with 'sonication but without interposing the CP-g plates between bare glass plates (SW)' method, the degree of close packing (DCP) and the degree of vertical orientation of zeolite-L crystals significantly increased when the monolayer assembly was carried out by SS method. 915 The above two results reveal that the strong agitation and the interposing CP-g substrate between the glass plates are very effective for increasing attachment rate and en-
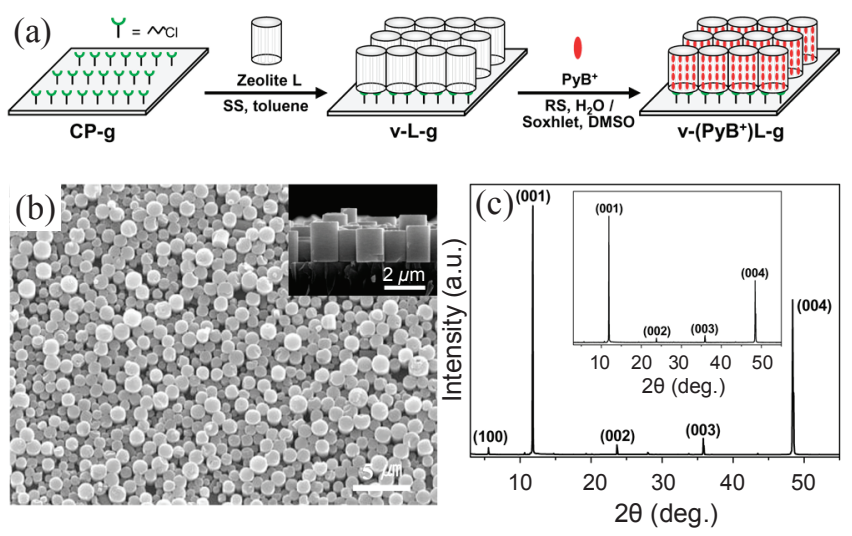

Figure 1. (a) A schematic illustration of preparation of vertically aligned $\mathrm{PyB}^{+}$-incorporating zeolite-L monolayer on $\mathrm{CP}-\mathrm{g}\left(\mathrm{v}-\left(\mathrm{PyB}^{+}\right) \mathrm{L}-\mathrm{g}\right)$. (b) SEM image of $\mathrm{v}-\left(\mathrm{PyB}^{+}\right) \mathrm{L}-\mathrm{g}$ showing the very tight close packing and vertical orientations. The inset represents the cross sectional SEM image. (c) X-ray diffraction pattern of $\mathrm{v}-\left(\mathrm{PyB}^{+}\right) \mathrm{L}-\mathrm{g}$ showing the diffraction lines from $(00 \mathrm{c})$ planes of zeolite-L with $\mathrm{c}=1,2,3$, and 4 at $2 \theta=11.9,23.8,35.9$, and $48.5^{\circ}$, respectively, and $\left(\begin{array}{lll}1 & 0 & 0\end{array}\right)$ plane of zeolite-L at $2 \theta=5.5^{\circ}$ even though weak intensity. The inset shows $\mathrm{X}$-ray diffraction pattern measured after soxhlet extraction procedure. 
hancing the degree of vertical orientation of zeolite-L crystals, respectively. Therefore, we believe that this SS method is superior to R, RS, and SW methods in terms of coverage, close packing, and uniform orientation during the monolayer assembly of long cylindrical microcrystals in the upright position. Consistent with the SEM images, the monolayers of $\mathrm{v}-\left(\mathrm{PyB}^{+}\right) \mathrm{L}$ crystals show strongly $\mathrm{X}$-ray diffraction (XRD) peaks at the $(0$ $0 \mathrm{c}$ ) planes (Figure 1c), indicating that the aligned direction is along to the c-axis of cylindrical zeolite-L crystal. The x-ray data revealed that the uniformity of the orientations on the $\sim 4 \mathrm{~cm}^{2}$ glass plates was higher than $97 \%$. Unusually, these $(00 \mathrm{c})$ peaks are accompanied by a XRD peak from the $\left(\begin{array}{lll}1 & 0 & 0\end{array}\right)$ plane even though weak intensity. The careful comparison of this XRD pattern with that of $\mathrm{v}-\left(\mathrm{PyB}^{+}\right) \mathrm{L}-\mathrm{g}$ obtained before the soxhlet extraction, further suggests that this $\left(\begin{array}{lll}1 & 0 & 0\end{array}\right)$ peak arises from detachment and mismatching of crystals aligned along to the c-axis during soxhlet extraction procedure (Figure 1c, inset).

According to the standard method described in our previous report, ${ }^{18}$ the surfaces of $\mathrm{PyB}^{+}$-incorporating zeolite-L crystals on glass substrate were subsequently treated with (3-aminopropyl)trimethoxysilane (AP-TMS) to tether 3-aminopropyl groups on their surfaces and to prevent the egress of the incorporated $\mathrm{PyB}^{+}$ions from the channels to the solution (glycerol) during the measurement of fluorescence spectrum. This aminopropyl-tethering $\mathrm{V}-\left(\mathrm{PyB}^{+}\right) \mathrm{L}-\mathrm{g}$ is denoted as $\mathrm{V}-\left(\mathrm{PyB}^{+}\right) \mathrm{L}^{\mathrm{AP}}-\mathrm{g}$. The normalized fluorescence spectra obtained from ' $\mathrm{PyB}^{+}$, ' $\mathrm{V}-$ $\left(\mathrm{PyB}^{+}\right) \mathrm{L}-\mathrm{g}$ ', and ' $\mathrm{V}-\left(\mathrm{PyB}^{+}\right) \mathrm{L}^{\mathrm{AP}}-\mathrm{g}$ ' in glycerol are shown in Figure $2 \mathrm{a}$ and denoted as $\mathrm{S}\left\{\mathrm{PyB}^{+}\right\}, \mathrm{S}\left\{\mathrm{v}-\left(\mathrm{PyB}^{+}\right) \mathrm{L}-\mathrm{g}\right\}$, and $\mathrm{S}\{\mathrm{v}-$ $\left.\left(\mathrm{PyB}^{+}\right) \mathrm{L}^{\mathrm{AP}}-\mathrm{g}\right\}$.

The maximum-emission wavelengths $\left(\lambda_{\mathrm{Emax}}\right)$ of the corresponding fluorescence spectrum were 576,574 , and $567 \mathrm{~nm}$, respectively. We note that the broader width of $\mathrm{S}\left\{\mathrm{V}-\left(\mathrm{PyB}^{+}\right) \mathrm{L}-\mathrm{g}\right\}$ and $\mathrm{S}\left\{\mathrm{V}-\left(\mathrm{PyB}^{+}\right) \mathrm{L}^{\mathrm{AP}}-\mathrm{g}\right\}$ bands relative to $\mathrm{S}\left\{\mathrm{PyB}^{+}\right\}$band is attributed to the presence of crystalline silicates. Since the inserted molecules are confined within narrow channels of zeolite-L, the $\mathrm{PyB}^{+}$ions in ' $\mathrm{v}-\left(\mathrm{PyB}^{+}\right) \mathrm{L}-\mathrm{g}$ ' and ' $\mathrm{V}-\left(\mathrm{PyB}^{+}\right) \mathrm{L}^{\mathrm{AP}}-\mathrm{g}$ ' are expected to have higher energy than those in glycerol solution. But, the similarity of $\lambda_{\mathrm{Emax}} \mathrm{S}$ of $\mathrm{S}\left\{\mathrm{PyB}^{+}\right\}$and $\mathrm{S}\left\{\mathrm{V}-\left(\mathrm{PyB}^{+}\right) \mathrm{L}-\mathrm{g}\right\}$ reveals that the $\mathrm{S}\left\{\mathrm{V}-\left(\mathrm{PyB}^{+}\right) \mathrm{L}-\mathrm{g}\right\}$ arose from randomly oriented $\mathrm{PyB}^{+}$ ions existing on the external surfaces or in glycerol solution instead of the narrow channel of zeolite-L. The $\lambda_{\text {Emax }}$ of $S\{\mathrm{~V}-$ $\left(\mathrm{PyB}^{+}\right) \mathrm{L}^{\mathrm{AP}}-\mathrm{g}$ \} was only blue-shifted for reason of the confinement effect of the $\mathrm{PyB}^{+}$ions by the narrow channel. Therefore, the treatment with 3-aminopropyl groups on zeolite-L surfaces is essential to prevent the egress of the incorporated $\mathrm{PyB}^{+}$ions and to confine $\mathrm{PyB}^{+}$ions residing within the channels of zeolite.

Figure $2 b$ shows the angle-dependent change of $I_{R-\max } / I_{R-\min }$ ratio, where $\mathrm{I}_{\mathrm{R} \text {-max }}$ and $\mathrm{I}_{\mathrm{R} \text {-min }}$ represent the maximum and minimum intensity of the spectrum at $\lambda_{\mathrm{Emax}}$ at various detection angles $(\theta s)$ when the respective $\mathrm{PyB}^{+}$ions of 'PyB ${ }^{+}$, ' $\mathrm{v}-\left(\mathrm{PyB}^{+}\right) \mathrm{L}-\mathrm{g}$ ', and ' $\mathrm{V}-\left(\mathrm{PyB}^{+}\right) \mathrm{L}^{\mathrm{AP}}-\mathrm{g}$ ' in glycerol were excited by circularly polarized light. Interestingly, a dramatic increase in $\mathrm{I}_{\mathrm{R}-\max } / \mathrm{I}_{\mathrm{R}-\mathrm{min}}$ ratio was observed from ' $\mathrm{V}-\left(\mathrm{PyB}^{+}\right) \mathrm{L}^{\mathrm{AP}}-\mathrm{g}$ ', which was 2.36 . The ratio correspond to over double value than those achieved by 'PyB' ${ }^{+}$(1.05) and ' $\mathrm{v}-\left(\mathrm{PyB}^{+}\right) \mathrm{L}-\mathrm{g}$ ' (1.12). Contrary to 'PyB' ${ }^{+}$' and ' $\mathrm{V}-\left(\mathrm{PyB}^{+}\right) \mathrm{L}^{\mathrm{AP}}-\mathrm{g}$ ' in glycerol, although not very accurate, the instant $\mathrm{I}_{\mathrm{R} \text {-max }} / \mathrm{I}_{\mathrm{R} \text {-min }}$ ratio was gradually decreased during the fluorescence spectrum measurement for ' $v-\left(\mathrm{PyB}^{+}\right) \mathrm{L}-\mathrm{g}$ ', where consequently resulted in the similar ratio with ' $\mathrm{PyB}^{+}$' in glycerol. We believe that this decrement is attributed to the release of the $\mathrm{PyB}^{+}$ions inserted into narrow channels of zeolite-L caused by the thermal heating induced by laser light irradiation. Thus, the above results and observations support that the $\mathrm{PyB}^{+}$ions of ' $\mathrm{V}-\left(\mathrm{PyB}^{+}\right) \mathrm{L}-\mathrm{g}$ ' could be located both glycerol and the external surface of zeolite-L crystals, contrasting with ' $\mathrm{PyB}^{+}$' and ' $\mathrm{v}-$ $\left(\mathrm{PyB}^{+}\right) \mathrm{L}^{\mathrm{AP}}-\mathrm{g}$ '.

For comparison between ' $\mathrm{V}-\left(\mathrm{PyB}^{+}\right) \mathrm{L}-\mathrm{g}$ ' and ' $\mathrm{v}-\left(\mathrm{PyB}^{+}\right) \mathrm{L}^{\mathrm{AP}}-\mathrm{g}$ ', we also investigated the vertical and horizontal components of the fluorescence spectrum obtained by exciting the their stacks with vertically and horizontally polarized laser lights (514.5 $\mathrm{nm})$, respectively. For convenience, they are denoted as $\mathrm{S}_{\mathrm{VV}}$, $\mathrm{S}_{\mathrm{VH}}, \mathrm{S}_{\mathrm{HV}}$, and $\mathrm{S}_{\mathrm{HH}}$, respectively. The first and second subscripts represent the orientation of the polarized incident light and the orientation of the polarizer to the detector, respectively.

As shown in Figure 3a, the corresponding anisotropic fluorescence spectra of ' $\mathrm{v}-\left(\mathrm{PyB}^{+}\right) \mathrm{L}-\mathrm{g}$ ' have very similar $\lambda_{\mathrm{Emax}}(574$ $\mathrm{nm}$ ) and band width. Considering the fact that all $\lambda_{\mathrm{Emax}} \mathrm{S}$ of $\mathrm{S}_{\mathrm{VV}}$, $\mathrm{S}_{\mathrm{VH}}, \mathrm{S}_{\mathrm{HV}}$, and $\mathrm{S}_{\mathrm{HH}}$ of $\mathrm{PyB}^{+}$ions in glycerol are located at $576 \mathrm{~nm}$, the above result supports that the $\mathrm{PyB}^{+}$ions of ' $\mathrm{V}-\left(\mathrm{PyB}^{+}\right) \mathrm{L}-\mathrm{g}$ ' have similar energy conformation and random distribution in solution, not inducing any energy transfer between $\mathrm{PyB}^{+}$ions and not doing anisotropic photoluminescence with a certain
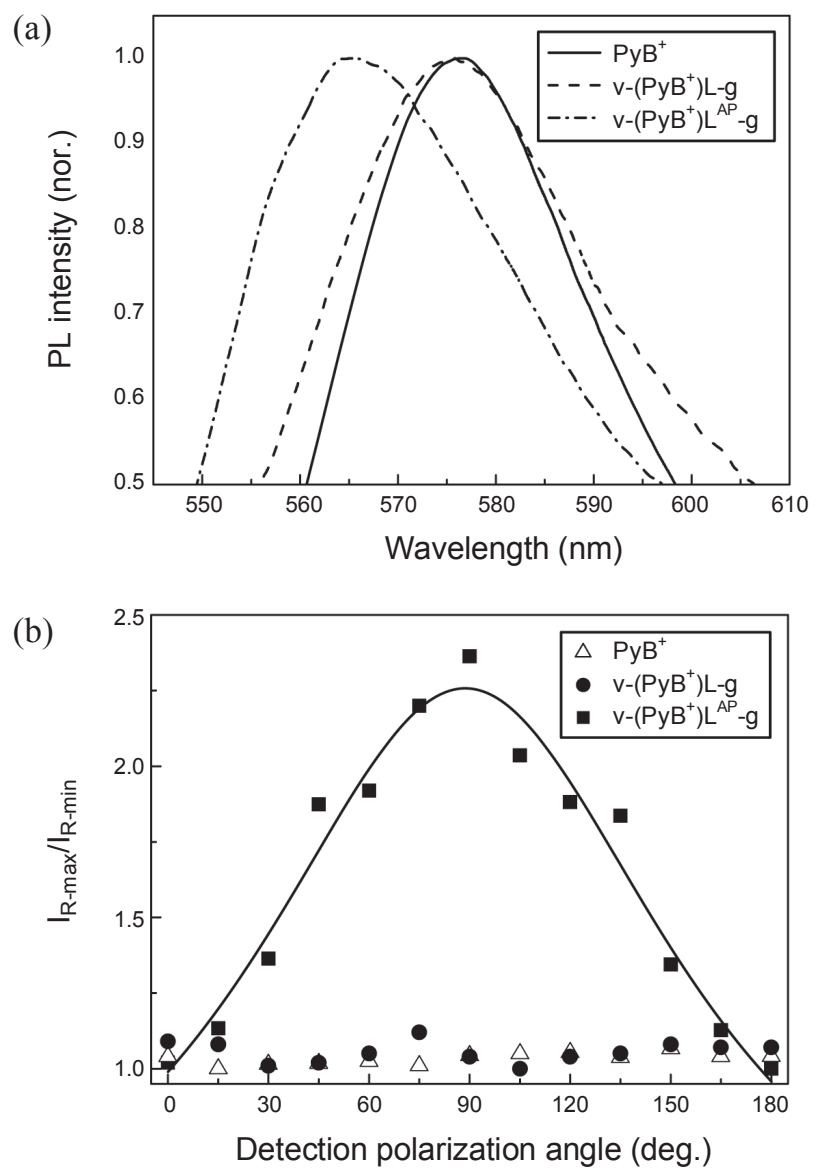

Figure 2. (a) Normalized fluorescence spectra and (b) angle-dependent change of $I_{R-\max } / I_{R-\min }$ ratio under circularly polarized excitation, obtained from 'PyB', ' $\mathrm{V}-\left(\mathrm{PyB}^{+}\right) \mathrm{L}-\mathrm{g}$ ', and ' $\mathrm{V}-\left(\mathrm{PyB}^{+}\right) \mathrm{L}^{\mathrm{AP}}-\mathrm{g}$ ' in glycerol, respectively. 
(a)

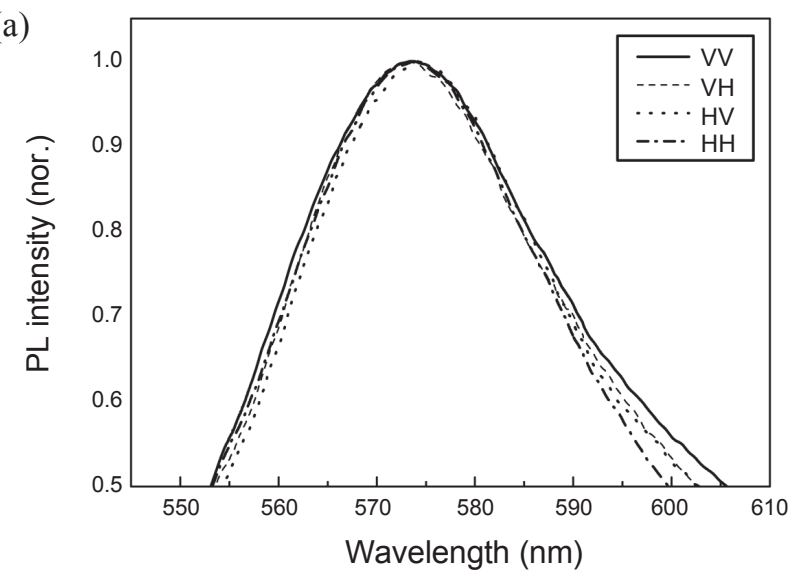

(b)

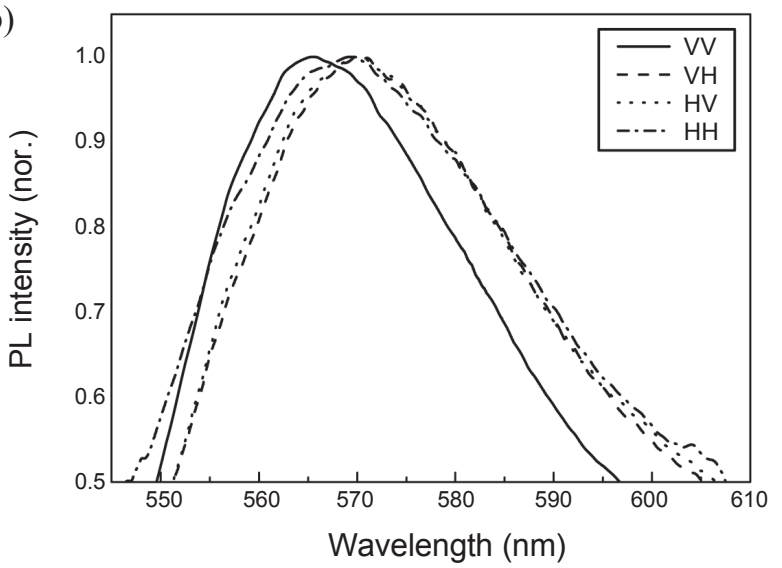

Figure 3. Normalized anisotropic fluorescence spectra $\left(\mathrm{S}_{\mathrm{VV}}, \mathrm{S}_{\mathrm{VH}}, \mathrm{S}_{\mathrm{HV}}\right.$, and $\left.\mathrm{S}_{\mathrm{HH}}\right)$ of ' $\mathrm{v}-\left(\mathrm{PyB}^{+}\right) \mathrm{L}-\mathrm{g}$ ' (a) and ' $\mathrm{v}-\left(\mathrm{PyB}^{+}\right) \mathrm{L}^{\mathrm{AP}}{ }_{-\mathrm{g}}$ ' (b) in glycerol, respectively.

direction, respectively. However, in the case of ' $\mathrm{v}-\left(\mathrm{PyB}^{+}\right) \mathrm{L}^{\mathrm{AP}}-\mathrm{g}$ ' (Figure $3 b$ ), the $\lambda_{\text {Emax }}$ are interestingly in the order of $\mathrm{S}_{\mathrm{VV}}<$ $\mathrm{S}_{\mathrm{VH}} \approx \mathrm{S}_{\mathrm{HV}} \approx \mathrm{S}_{\mathrm{HH}}$, which are $567,570,570$, and $570 \mathrm{~nm}$, respectively. This result shows that the energy of excited $\mathrm{PyB}^{+}$ ions is increasing as increasing the degree of confinement. Considering that $\mathrm{PyB}^{+}$ions of ${ }^{\mathrm{V}} \mathrm{V}-\left(\mathrm{PyB}^{+}\right) \mathrm{L}^{\mathrm{AP}}-\mathrm{g}$ ' are excited only by vertically polarized light and the fluorescence from them must also be vertically polarized, the facts that band width of $\mathrm{S}_{\mathrm{VH}}$, $\mathrm{S}_{\mathrm{HV}}$, and $\mathrm{S}_{\mathrm{HH}}$ are broader than that of $\mathrm{S}_{\mathrm{VV}}$ and their $\lambda_{\mathrm{Emax}} \mathrm{S}$ are longer than that of $\mathrm{S}_{\mathrm{Vv}}$ further confirm that $\mathrm{S}_{\mathrm{VH}}, \mathrm{S}_{\mathrm{HV}}$, and $\mathrm{S}_{\mathrm{HH}}$ arise from the external $\mathrm{PyB}^{+}$ions, and their conformations are more diverse than that of $\mathrm{PyB}^{+}$ions intercalated within the channels of zeolite-L. Therefore, the broad band width and shorter $\lambda_{\mathrm{Emax}}$ of $\mathrm{S}_{\mathrm{VH}}$ relative to those of $\mathrm{S}_{\mathrm{VV}}$ further support a directional energy transfer from intrachannel $\mathrm{PyB}^{+}$ions to external $\mathrm{PyB}^{+}$ions. Interestingly, the direction of energy transfer is the opposite to the case of polymer-containing mesoporous silica ${ }^{19-21}$

For more quantitative interpretation of energy transfer among the intrachannel and external $\mathrm{PyB}^{+}$ions, we investigate the angle-dependent changes of $\mathrm{I}_{\mathrm{V} \theta} / \mathrm{I}_{\mathrm{VH}}$ and $\mathrm{I}_{\mathrm{H} \theta} / \mathrm{I}_{\mathrm{HV}}$ ratios, where $\mathrm{I}_{\mathrm{V} \theta}$ and $\mathrm{I}_{\mathrm{H} \theta}$ represent the intensity of the spectrum of ' $\mathrm{PyB}^{+}$, ' $\mathrm{v}-\left(\mathrm{PyB}^{+}\right) \mathrm{L}-\mathrm{g}^{\prime}$, and ' $\mathrm{v}-\left(\mathrm{PyB}^{+}\right) \mathrm{L}^{\mathrm{AP}}-\mathrm{g}^{\prime}$ ' in glycerol at $\lambda_{\mathrm{Emax}}$ at various detection angles $(\theta \mathrm{s})$ under vertical and horizontal exci- (a)

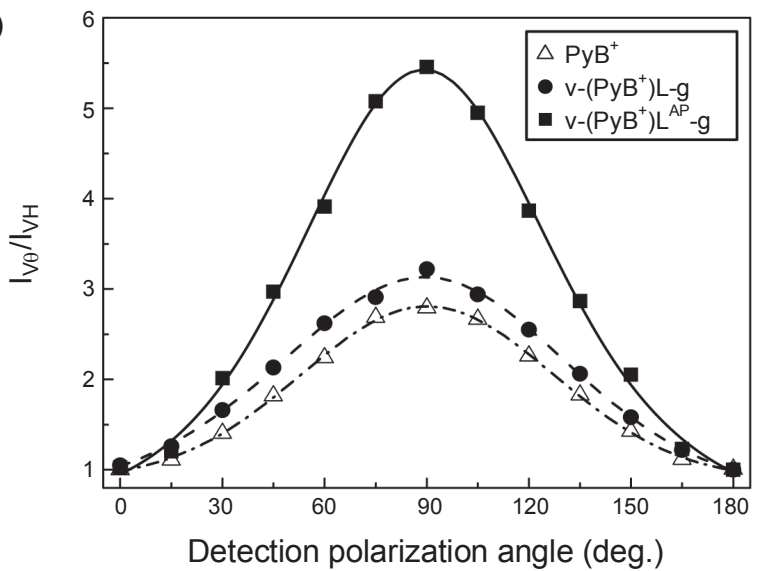

(b)

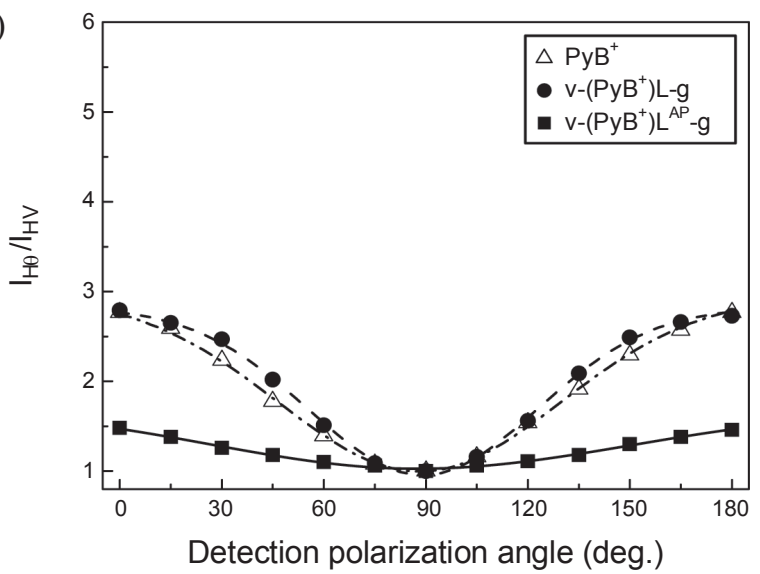

Figure 4. Angle-dependent changes of $\mathrm{I}_{\mathrm{V} \theta} / \mathrm{I}_{\mathrm{VH}}$ (a) and $\mathrm{I}_{\mathrm{H} \theta} / \mathrm{I}_{\mathrm{HV}}$ (b) ratios under vertical and horizontal excitation, respectively, obtained from 'PyB ${ }^{+}$, , ' $\mathrm{v}-\left(\mathrm{PyB}^{+}\right) \mathrm{L}-\mathrm{g}$ ', and ' $\mathrm{v}-\left(\mathrm{PyB}^{+}\right) \mathrm{L}^{\mathrm{AP}}{ }^{\mathrm{P}}$-g' in glycerol, respectively.

tation, respectively. In Figure $4 \mathrm{a}, \mathrm{I}_{\mathrm{V} \theta} / \mathrm{I}_{\mathrm{VH}}$ ratios were increasing as shifting from 'PyB ${ }^{+}$' (2.79) to ' $\mathrm{v}-\left(\mathrm{PyB}^{+}\right) \mathrm{L}-\mathrm{g}$ ' (3.22), and to ' $\mathrm{v}-\left(\mathrm{PyB}^{+}\right) \mathrm{L}^{\mathrm{AP}}-\mathrm{g}$ ' (5.46) at a vertical detection angle $\left(90^{\circ}\right)$. Contrary to the tendency to $\mathrm{I}_{\mathrm{V} \theta} / \mathrm{I}_{\mathrm{VH}}$ ratio, $\mathrm{I}_{\mathrm{H} \theta} / \mathrm{I}_{\mathrm{HV}}$ ratio of ${ }^{\mathrm{v}} \mathrm{v}-\left(\mathrm{PyB}^{+}\right)$ $\mathrm{L}^{\mathrm{AP}}-\mathrm{g}$ ' (1.48) is lower than those of 'PyB ${ }^{+}$, $(2.79)$ and ' $\mathrm{v}-\left(\mathrm{PyB}^{+}\right)$ L-g' (2.79), as shown in Figure 4b. We believe the above changes of $\mathrm{I}_{\mathrm{V} \theta} / \mathrm{I}_{\mathrm{VH}}$ and $\mathrm{I}_{\mathrm{H} \theta} / \mathrm{I}_{\mathrm{HV}}$ ratios in case of ${ }^{6} \mathrm{~V}-\left(\mathrm{PyB}^{\dagger}\right) \mathrm{L}^{\mathrm{AP}}-{ }_{-}$' resulted from the following two; higher molar ratio of vertically aligned intrachannel $\mathrm{PyB}^{+}$ions and shorter distance among external $\mathrm{PyB}^{+}$ions. The former is quite reasonable from the sense that polar molecules absorb and emit light along to their dipole moments axis. Since the dipole moments of the intrachannel $\mathrm{PyB}^{+}$ions of ' $\mathrm{v}-\left(\mathrm{PyB}^{+}\right) \mathrm{L}^{\mathrm{AP}}-\mathrm{g}$ ' with higher molar ratio are vertically oriented, they are excited only by vertically polarized light and the fluorescence from them must also be vertically polarized.

And, compared with the external $\mathrm{PyB}^{+}$ions of ' $\mathrm{v}-\left(\mathrm{PyB}^{+}\right) \mathrm{L}-\mathrm{g}$ ' which are movable like as ' $\mathrm{PyB}^{+}$', ones of ' $\mathrm{v}-\left(\mathrm{PyB}^{+}\right) \mathrm{L}^{\mathrm{AP}}{ }_{-} \mathrm{g}$ ' are restricted to their mobility on external surface of zeolite, which are induced the distance between $\mathrm{PyB}^{+}$ions to be close each other. Based on the above mentioned, since the shorter distance among external $\mathrm{PyB}^{+}$ions accelerates the loss of initial anisotropic luminescence through energy transfer one another, $\mathrm{I}_{\mathrm{H} \theta} /$ $\mathrm{I}_{\mathrm{HV}}$ ratio of ${ }^{\prime} \mathrm{V}-\left(\mathrm{PyB}^{+}\right) \mathrm{L}^{\mathrm{AP}}{ }_{-} \mathrm{g}$ ' becomes to be lower than those of 
'PyB' ${ }^{+}$, and ' $\mathrm{V}-\left(\mathrm{PyB}^{+}\right) \mathrm{L}-\mathrm{g}$ ', despite the small mobility of external $\mathrm{PyB}^{+}$ions (Figure $4 \mathrm{~b}$ ).

Interestingly, our anisotropic luminescence ratio (5.46) obtained from the ' $\mathrm{V}-\left(\mathrm{PyB}^{+}\right) \mathrm{L}^{\mathrm{AP}}-\mathrm{g}$ ' is higher than the dichroic ratio of 4.51 obtained from polymer-containing mesoporous silica. ${ }^{19}$ Compared with polymeric fluorescent, it is expected that $\mathrm{PyB}^{+}$ ions relatively easy to intercalate and be aligned within porous materials due to small size and light weight. And, based on the fact that our surface treatment of ' $\mathrm{v}-\left(\mathrm{PyB}^{+}\right) \mathrm{L}-\mathrm{g}$ ' is crucial for preventing the egress of the incorporated $\mathrm{PyB}^{+}$ions from the channels to the solution, we believe that it plays an important role to enhance the anisotropic luminescence.

\section{Conclusion}

Here, we have described that the vertically aligned zeolite monolayer can be applied as novel supramolecularly organized systems for the demonstration of anisotropic photoluminescence in high dichroic ratios, to study energy transfer dynamics between the internal and external fluorophores, and to develop zeolite-based advanced materials. This current study provides insight into molecular interactions that can be used for the future design of optoelectronic device in nanometer size, it also provides us with a unique opportunity to explore the photophysics of isolated, oriented organic dye.

Also, this report shows that isolating of organic dye through surface treatment can suppress intermolecular exciton formation, thus enhancing the generation of emissive intramolecular species and potentially improving the performance of dyes based optoelectronic devices.

Acknowledgments. We are grateful to Prof. Kyung Byung Yoon for assistance with characterization of ordered zeolite-L monolayer and helpful discussions to all figures. And, we thank
Prof. Hyeonsik Cheong and Hyunjin Lim for assistance with measurement of polarized fluorescence spectroscopy and helpful discussions.

\section{References}

1. Hagler, T. W.; Pakbaz, K.; Heeger, A. J. Phys. Rev. B 1994, 49, 10968.

2. Brinkmann, M.; Wittmann, J.-C. Adv. Mater. 2006, $18,860$.

3. Sluch, M. I.; Pearson, C.; Petty, M. C.; Halim, M.; Samuel, I. D. W. Synth. Met. 1998, 94, 285.

4. Chen, X.; Lenhert, S.; Hirtz, M.; Lu, N.; Fuchs, H.; Chi, L. Acc. Chem. Res. 2007, 40, 393.

5. Rudick, J. G.; Percec, V. Acc. Chem. Res. 2008, 41, 1641.

6. Hung, A. M.; Stupp, S. I. Langmuir 2009, 25, 7084.

7. Yanagi, H.; Okamoto, S. Appl. Phys. Lett. 1997, 71, 2563.

8. Calzaferri, G.; Huber, S.; Maas, H.; Minkowski, C. Angew. Chem. Int. Ed. 2003, 42, 3732.

9. Lee, J. S.; Lim, H.; Ha, K.; Cheong, H.; Yoon, K. B. Angew. Chem. Int. Ed. 2006, 45, 5288

10. Lim, H.; Cheong, H.; Lee, J. S.; Yoon, K. B. J. Kor. Phys. Soc. 2007, 51, 1583 .

11. Lim, H.; Cheong, H.; Lee, J. S.; Yoon, K. B. J. Kor. Phys. Soc. 2008, 53, 2328.

12. Komori, Y.; Hayashi, S. Chem. Mater. 2003, 15, 4598.

13. Yoon, K. B. Bull. Korean Chem. Soc. 2006, 27, 17.

14. Kulak, A.; Lee, Y.-J.; Park, Y. S.; Yoon, K. B. Angew. Chem., Int. Ed. 2000, 39, 950

15. Lee, J. S.; Ha, K.; Lee, Y.-J.; Yoon, K. B. Adv. Mater. 2005, 17, 837.

16. Lee, J. S.; Kim, J. H.; Lee, Y. J.; Jeong, N. C.; Yoon, K. B. Angew. Chem. Int. Ed. 2007, 46, 3087.

17. Lee, Y.-J.; Lee, J. S.; Yoon, K. B. Micro. Meso. Mater. 2005, 80, 237.

18. Jeong, N. C.; Kim, H. S.; Yoon, K. B. Langmuir 2005, 21, 6038.

19. Nguyen, T.-Q.; Wu, J.; Doan, V.; Schwartz, B. J.; Tolbert, S. H. Science 2001, 288, 652.

20. Wu, J.; Gross, A. F.; Tolbert, S. H. J. Phys. Chem. B 1999, 103, 2374.

21. Schwartz, B. J. Annu. Rev. Phys. Chem. 2003, 54, 141. 